\title{
HIGH PREVALENCE OF COMORBIDITIES, IMPAIRED DAYLY LIVING, AND METABOLIC EQUIVALENT IN PATIENTS WITH GRANULOMATOSIS WITH POLYANGIITIS
}

\author{
Sarah Luiza Gomes da Silva ${ }^{1}$, Alexandre Moura dos Santos ${ }^{1, \star}$, Rosa Maria Rodrigues Pereira ${ }^{1}$, Samuel Katsuyuki Shinjo ${ }^{1}$ \\ 1.Universidade de São Paulo, São Paulo (SP), Brazil. \\ *Corresponding author: alexandrestos@usp.br
}

\section{BACKGROUND}

Granulomatosis with polyangiitis (GPA) is a primary systemic vasculitis that may cause several systemic impairments, possibly reducing the level of activities of daily living (ADLs); therefore, we aimed to assess the prevalence of comorbidities and their health outcomes.

\section{METHODS}

This cross-sectional study included 27 patients with GPA (EULAR, 2018) who were sex and age-matched to 54 healthy individuals. The ADLs was assessed using HAQ, disease activity using BVAS, metabolic equivalent using IPAQ-SF, and fatigue using the fatigue severity scale (FSS).

\section{RESULTS}

The demographic features, disease status, comorbidities, and current treatment of patients with GPA and controls are shown in Table 1. The current age, body mass index, ethnicity and gender distribution were comparable between groups. The duration of the disease was 10.0 (4.0-15.0) years, and 4 patients had disease activity. Patients had a higher prevalence of systemic arterial hypertension and dyslipidemia. In addition, diabetes mellitus, heart disease, and stroke occurred only in patients. Furthermore, patients presented impairment in ADLs $(p=0.011)$, and the metabolic equivalent/IPAQ-SF $(p=0.003)$, whereas the distribution of fatigue frequency was similar in both groups $(p>0.05)$.

\section{CONCLUSION}

Patients with GPA have increased comorbidities with impaired ADLs and reduced metabolic equivalent. Therefore, studies that develop strategies to contain comorbidities and improve the quality of life of these patients are needed.

\section{FUNDING}

Support by FAPESP Grant No. 2019/11776-6 and CNPq Grant No. 303379/2018-9 to SKS.

\section{KEYWORDS}

Granulomatosis with polyangiitis, Systemic vasculitis, Patient outcomes, Comorbidities, Physical activity. 
Table 1. Demographic features, disease status, comorbidities, drug treatment, and their health outcomes between GPA and healthy individuals (Control)

\begin{tabular}{|c|c|c|c|}
\hline & GPA $(n=27)$ & Control $(n=54)$ & p-value \\
\hline Age (years) & $54.0(40.0-64.0)$ & $52.0(47.0-57.3)$ & 0.551 \\
\hline Body mass index $\left(\mathrm{kg} / \mathrm{m}^{2}\right)$ & $28.3(23.8-31.2)$ & $26.5(23.0-29.7)$ & 0.228 \\
\hline White ethnicity & $15(55.6)$ & $41(75.9)$ & 0.106 \\
\hline Female gender & $19(70.4)$ & $47(87.0)$ & 0.127 \\
\hline Duration of disease (years) & $10.0(4.0-15.0)$ & 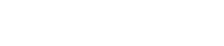 & 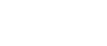 \\
\hline Disease activity & $4(16.0)$ & Q & 凶 \\
\hline \multicolumn{4}{|l|}{ Prednisone } \\
\hline Current use & $13(48.2)$ & 凶 & 凶 \\
\hline Current dose (mg/day) & $5.0(2.5-16.5)$ & 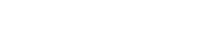 & 凶 \\
\hline Immunosuppressive or immunobiological drugs & $21(77.8)$ & & \\
\hline \multicolumn{4}{|l|}{ Comorbidities/habits } \\
\hline Systemic arterial hypertension & $19(70.4)$ & $10(18.5)$ & $<0.001$ \\
\hline Dyslipidemia & $11(40.7)$ & $9(16.7)$ & 0.036 \\
\hline Diabetes mellitus & $6(22.2)$ & 0 & - \\
\hline Heart disease & $4(14.8)$ & 0 & - \\
\hline Stroke & $2(7.4)$ & 0 & $\otimes$ \\
\hline Current smoker & $3(11.1)$ & $1(1.9)$ & 0.105 \\
\hline HAQ (0.00-3.00) & $0.25(0.00-0.75)$ & $0.00(0.00-0.25)$ & 0.011 \\
\hline FSS (> 28 points) & $19(70.4)$ & $32(59.3)$ & 0.464 \\
\hline \multicolumn{4}{|l|}{ IPAQ - SF } \\
\hline Low & $16(59.3)$ & $17(31.5)$ & 0.031 \\
\hline Moderate & $9(3.3)$ & $16(29.6)$ & 0.932 \\
\hline High & $2(7.4)$ & $21(38.4)$ & 0.007 \\
\hline Metabolic equivalent & $792(240-1200)$ & 1683 (567-3811) & 0.003 \\
\hline
\end{tabular}

Note. Data expressed as median (25th-75th) or frequency (\%). 